\title{
Martin Andrew
}

\section{Forewarned is forearmed: The brave new world of (Creative) Writing online}

\begin{abstract}
Online Writing courses, including Creative Writing programs, have been delivered in Australia for more than a decade. While most providers of online writing programs offer units in either a flexible or blended transmission model or with a choice of online or face-to-face $(F 2 F)$ modality, there is pressure on universities to increase the proportion of programs delivered using e-learning. With this trend in mind, I investigate some of the germinal theoretical and pedagogical ideas impacting on the online delivery of Writing in a Master of Arts program taught at Swinburne University of Technology in Melbourne, Australia. These concepts include the social constructivist notions of community of practice and imagined community. In narrating my story of developing and teaching units for online delivery, I draw on my empirical studies $(2009,2010)$ for narratives from tutors and students. Here, their voices become part of my narrative enquiry: their insights inform the story of what I learned from engaging in teaching and learning (Creative) Writing online. I consider the post-structural notion that writers' identities are motivated by desire, in flux and sites of struggle. This applies to all people enrolling in writers' programs, whether online or F2F. They are seeking increased agency in their desires to be and become more accomplished writers. It is as important for an online delivery to realise this as a F $2 F$ one. I also issue a challenge for (Creative) Writing programs to consider more deeply the pedagogical potential of online workshopping while acknowledging it can only be an emulation of F2F environments. I conclude that for a creative discipline like Writing, course designers and educators need to look beyond schematic social constructivist models of learning where learners experience linear trajectories to one which allow narratives of being and becoming that more fully understand the investment of people enrolling in Writing programs.
\end{abstract}

Keywords: Writing education, online pedagogy,community of practice, Creative Writing, workshopping

\section{Introduction: Creating identity texts}

In the debate following the announcement of the demise of RMIT's Professional Writing and Editing (PWE) program after 21 years, Malcolm King wrote in the journal Online Opinion: 'Clearly, programs have to be profitable but there is no need to crush the soul out of them' (King 2012). It survives, but as an associate 
degree. In happier times Claire Renner had written in RMIT's online Edjournal: 'Overwhelmingly, our students say that one of the most valuable things they get out of the program is sharing their work with other like-minded students' (Renner 2008). In an article in The Writer's Chronicle, Steve Healey (2009) advises creative Creative Writing teachers to face the bogey of dreaded capitalism by aligning our teaching goals with those of students' life goals. His message is: the market is there, but get real. For instance, face-to-face (F2F) deliveries of Creative Writing programs face conundrums not only born of the need for profits, but also the fact that its 'signature pedagogy' - workshopping is resource-intensive, needing tutorial rooms and physical resources as well as the human capital of skilled tutors and invested students. Imagining if programs such as this one could have been saved if they were online is vain hypothesising, but considering partially or even wholly teaching the discipline of (Creative) Writing online is foresightful. Wise programs continue to investigate the advantages and disadvantages of using blended or converged models (Conway-Herron \& Morgan 2008). Janie Conway-Herron and Chris Morgan suggest that students feel short-changed by substituting online workshops for F2F, opining that 'the intensive workshop is the best way in which to provide an immersive, interactive, developmental experience for students' (9). Therefore, putting (Creative) Writing programs online involves grappling with research questions Marcelle Freiman (2002), Heather Beck (2004), LC Breuch (2004) and Claire Bell, James Cooper and Mark Worthing (2010) touch on: Can online workshopping be as beneficial for creative writers as F2F workshops, and if so, how?

This paper is a contribution in that direction, maintaining that the Creative Writing discipline's need to investigate online pedagogies, including possibilities for workshopping, is essential. Its aims are to investigate the features of quality online programs in Writing and consider what theoretical structures inform them and their pedagogies. Specifically, I ask how current thinking on online community impacts on (Creative) Writing pedagogy and on student identities.

In writing this narrative enquiry, I use as data the 12-year history of Swinburne University's online MA in Writing (Andrew \& Arnold 2011), my lifetime enthusiasm for learning in community and my own reflective records of my experience in the development and delivery of online teaching in Writing. These, of course, are suffused by the insights of tutors and students, stories told elsewhere (Andrew 2009, Andrew \& Arnold 2011) and rewoven into this fresh narrative. This acknowledges the co-constructed nature of narratives. I border on autoethnography, placing 'the self in a social context' (Reed-Danahay 1997: 9) and aim to transcend 'mere narration of self to engage in cultural analysis and interpretation' ( $\underline{\text { Chang 2008: 43) }}$, specifically the culture of online (Creative) Writing programs. I also survey research on online pedagogy for (Creative) Writing, focussing on the social constructivist concepts of community of practice and imagined community as these seem particularly important for the pedagogical emphases on workshops and student-directed learning. I aim to develop the argument that for teaching Writing online, social constructivist models are insufficient as the stand-alone panacea they may currently seem to be to content-based disciplines. As Cathy Day indicates in her consideration of where Creative Writing pedagogies are going next:

while some see the exponential growth of creative writing programs and online writing communities as a harbinger of doom, I think it's a cause for celebration that so many people feel authorized to write and are interested in learning to do so. (Day, Leahy_\& Vanderslice 2011) 
We can take heart from Healey's (2009) argument that the 'opposition between cultivated humanism and vulgar marketplace, between impractical creativity and practical profitability, is rapidly disappearing' (4) and from studies of new possibilities for teaching Writing in the 21st century (Donnelly 2010; Herrington, Hodgson, \& Moran 2009). Anecdotally, the market for (Creative) Writing exists, but we have to nurture it. In the necessary future world of online delivery we can achieve this by better understanding the theories and pedagogies of online delivery and its potential for community-building and for workshops - at least in an emulated form.

At this point I admit drawing on studies from the wide world of 'practical' Writing (such as Herrington, Hodgson \& Moran 2009) as well as the rarefied world of 'impractical' Creative Writing (such as Donnelly 2010) in order to show possible pedagogical synergies, particularly in the application of insights from online teaching, while maintaining throughout that 'identity' is reflected more in Creative Writing texts than in those of the wider discipline of Writing. This also allows me to apply studies tested in Writing (such as Breuch 2004) to our wider teaching and learning context. When I speak of '(Creative) Writing' for the discipline and '(creative) writing' for the practice or activity, you'll know I'm in the liminal zone pertinent to both, open to the possibility that 'creative Writing'also exists.

Alongside theoretical understanding of how learning develops via community building and scaffolding in online environments (Cho \& Schunn 2007), (Creative) Writing programs need to emphasise that writing, particularly creative writing, is an act of identity formation, quite literally involving face and voice (Ivanic 1998) and an ontological exercise (Bizzaro 2010). Like Polkinghorne (1998), I hold that narratives, such as the one you now read, contain, or even are, people's identities. (Creative) Writing texts are identity texts, and their writers are highly invested not only in the instrumental need to pass the course or even the imagined integrative desire to join that elite group who can call themselves 'writers', but most of all in seeing how far they can come from the moment they hatch the idea to when their manuscript is ready. Learning Creative Writing, Julia Colyar (2009) reminds us, is about being and becoming; students are invested in being and becoming writers. Hence, I also present a discussion of the kinds of post-modern and post-structuralist notions of identity that sit alongside social constructivist trajectories of learning evident in students' journeys of learning writing.

\section{One model of online Writing pedagogy and delivery}

In the panel discussion, 'Where are we going next? A conversation about Creative Writing pedagogy' (Day, Leahy \& Vanderslice 2011), Stephanie Vanderslice reminds us there are many niche places in the market for a range of (Creative) Writing programs. Each Writing program in Australian universities and beyond, delivers programs reflective of their practical resources and specialist staff. Swinburne University's 12-unit MA aims to encompass students' interested in being and becoming both academics and (more often) professional writers. It offers both an academic-track and a professional track, creating, delivering, assessing and updating such a program poses a range of challenges, all of them involving fusing the kinds of appropriate educational theory with a range of practical, deliverable and innovative pedagogical interventions (Herrington et al 2009).

This section first describes the pedagogical principles underpinning each unit in the MA and then describes how the concept of critical friendship is introduced 
in the first unit and sustained until its final one. In the process, I exemplify some of the aspects of the course that emulate elements of workshopping, although I stop short of suggesting the pedagogies can be as effective as those of F2F environments. They are emulations, but they do have pedagogical value and impact. In the following section, I will more closely articulate the connection between what we do and the educational and ontological theories that undepin it.

In order to deliver a sequenced program of broad appeal and relevance, each of the 12 units are built around a major writing assignment in week 10 of the 12week program. The various units cover such subjects as real life writing, research for writers, writing history, screenwriting and writerly identities, and are sequenced so that a major 20,000-word portfolio of writing is submitted in the final units. Units comprise sequences of 12 lectures by lecturer-writers, among them tenured and sessional staff and invited writer-speakers from professional worlds. I call them 'writer-speakers' because each unit contains a downloadable written lecture as well as a podcasted video lecture that gives the lecturer a presence, a face, a voice, in the online delivery space. The written lectures range to around 5,000 words. Each is divided into a range of subsections, and each uses hyperlinks to encourage simultaneous autonomous exploration beyond the lecture. Those written by lecturers deal more to the theoretical and cultural underpinnings of text creation and locate each unit's textual creation: a piece of researched writing, a work infused by history, a critique of a peer's writing, a sequence of reflective writings, to name a few assessed outputs. Those commissioned by industry professionals might have practical or market-led approaches, and be grounded in insider knowledge from industry.

The video lectures do not replicate the written lecture, but employ dialogic formats like scripted Q\&As, spontaneous interviews and devil's-advocacy-style platonic dialogues. Hence, we create audiovisual texts that interact with and interrogate the written lecture. In learning design terms, they either supplement or complement the written lecture, providing other and sometimes multiple voices. In weeks 5, 8 and 12 there may be videos functioning as scaffolding, discussing research planning, the qualities of successful writing or the principles of peer critique. As well as being more interactive and appealing to a range of learning styles, this pedagogical model promotes critical responsiveness and deep thinking (Freiman 2002).

Reflective thinking is obviously crucial to teaching and learning Writing and is challenging to achieve online. For this reason, there are weekly tutorials, with students participating in discussion forums, responding to cues and questions based on fusing together and understanding the week's lecture input, readings and hyperlinks. Throughout the units in the MA, there is a general structure: In week 5, there is a virtual assignment planning tutorial in the space of the discussion forum; in week 8 a virtual peer critique workshop, and in week 12 a reflective space where individuals reveal their learning across the unit and share how they resolved dilemmas.

Critical thinking is central too. Students are required not only to submit their own responses - weekly texts of the self - but also to respond to the texts of others. Through such responsiveness, students begin to critique and build trust, in turn building online partnerships and micro-communities. They establish critical friendships at the outset and these expand into online communities as they move through the 12 units, 'meeting' more like-minded writers in the process. By the time students reach their final unit, they have developed trusting collaborations with particular critical friends through both reviewing others' weekly contributions and through participation in asynchronous peer critiques. 
Peer critique, moderated to an appropriate degree by the tutor, emulates workshopping.

How does this culture of trust develop? The program begins with 'Critical friends', a unit requiring individuals to collaborate creatively on texts by writing each other reader's reports and then considering their critical friend's observations when writing the draft the tutor will assess. Writers of texts are free to reject (or partially apply) feedback: the point is to reflect on the critical. In a similar context, Freiman (2002) noted 'the student generated-text is engaged with socially, by being read and responded to, creating a context for learning through social negotiation' (4). Pedagogically, nurturing "a critical sensibility' is as crucial as teaching the details of good writing (Vanderslice 2006: 52).

In MA units, peers function as peer reviewers, offering feedback at mechanicaldiscursive, readerly-responsive and critical-analytic levels: the editor, the audience, the assessor. Emphatically, it is crucial to show students how to do the work of the workshop: to interpret and evaluate (Bizzaro 2010). The following sample of the bullets in the checksheet given to critical friends to ensure their feedback is on target comes from a level 7 portfolio-focussed unit where peers workshop 20 or so pages inter alia. Peers are asked to write:

- What you find effective about the piece

- How you responded as a reader to different aspects of the piece, and why you responded in that way

- What effects your friend achieves, and what they could do to make the piece more effective

- How you think your friend uses narrative and narrative voice

- Whether structure, language, vocabulary and syntax 'fit' throughout the piece.

While space allows a mere sampling of teaching material, this illustrates the pedagogical intervention of ensuring peer critiquing, interpreting and evaluating reflects the tutor's guidance.

What do units look like architecturally? As mentioned earlier, the MA program uses the LMS Blackboard as an environment for delivering content, for facilitating the discussion board forums and for exchanging texts for critically friendly review. The lectures are created using Adobe Contribute, which allows lecturers to place their material directly on the WWW. The LMS provides the locus for attendance, participation, socialisation and learning. Users negotiate the interface using a range of buttons on the left-hand side, taking them to a corresponding hyperlinked menu listing any Word/PDF document or information screen the lecturer-convenor wants to direct people to, from the unit outline to the assessment documents to the unit website. Within the unit website the 12 full-text lectures nestle, along with links to the accompanying audiovisual text. For each of these there is a weekly question in a virtual tutorial comprising 12-16 students.

Pedagogically speaking, what does critical friendship look like? 'Critical friendship' derives from teacher education, where critical friends engage with each other communicatively, mutually, questioningly in a common goal of selfimprovement (Hatton \& Smith 2005). Critical friendships are forged early in a 12-week course between participants within asynchronous discussion forums, largely in the responsive spaces where students comment on their peers' answers to weekly questions. In doing this, they discover synergies and synchronicities among each other, building empathy. The forum is fuelled by questions designed to provoke responsiveness, creativity or reflectivity. It is 
also a place for student assertions and exchanges. In week 2 of the first unit, 'Critical friends', for example, students participate in a discussion aimed at unpacking concepts and understanding theory-grounded metalanguage that will infuse the MA:

In the light of the information and ideas canvassed in this week's lecture, the links provided above and any links you can provide, write up to 500 words about how you might understand the terms 'the writerly self' and 'the self as critic' and comment on the usefulness of the strategies of critiquing by self and others. (Critical Friends unit outline, week 2).

In weeks 5,6 and 8 of the 12th and final unit, one focussed on the production of a final writing folio, students participate in student-mediated workshop sessions in which they comment on and evaluate each others' plans and methodologies (week 5), practice-led insights developed during the 12 units (week 6) and sections of their portfolio texts (week 8). They are told the during the sessions they will:

- apply their critical potential to their own and others' work;

- participate actively in a critical friendship;

- come to understand practice-led research more deeply by seeing it from others' perspectives;

- apply their learning about writing to the process of giving readerlywriterly feedback to others;

- develop responsiveness to ideas about their work from others within the writing community.

They are given specific task descriptions for each forum, and tutors monitor (check attendance, response length and rate and take appropriate follow up action), mediate (ensure the culture of the group is free of inappropriate commentary and conflict) and moderate these forums. In e-moderating, Writing tutors use the kinds of responsive and reflective critical strategies familiar to F2F workshopping. In online tutorials e-moderators also employ such strategies as summarising (creating a group response directing participants to others' thinking) and weaving (building on the participants' current knowledge with further questioning or references). Using these strategies ensure each individual's attention is drawn to the insights of the group and the strengths of individuals within it, building a shared repertoire, and encouraging individuals to think one step beyond that square, perhaps by finding resonance with another's thinking.

Provided skilled e-moderation takes place, discussions can help students feel they are part of a developing e-community (Andrew 2010; Salmon 2000). If there is time in e-moderators' workloads and if time zones are manageable, there are synchronous chatzones. Alternatively, tutors can set up MSN Messenger groups, negotiate a time, and conduct a virtual office hour. In time, the tutor might leave this negotiated space, allowing students to use it for critical friendship. Insights are shared via discussions and trust is built. With trust comes a willingness to share and collaborate. For Palloff and Platt (2005) collaboration accomplishes such outcomes as addressing all learning styles and cultures, assisting with deeper knowledge generation, promoting creativity and initiative and allowing shared goals for the foundation of a learning community (6-7).

Developing community is fundamental to creating a place of trust, but what many participants seek from (Creative) Writing courses are opportunities to develop as individuals, to find their real voice and gain confidence in it (Ivanic 
1998; Vanderslice 2006). Workshops are the customary pedagogic means of building voice in (Creative) Writing courses by doing and discussing (Vanderslice 2006). Interrogation of our own texts and those of our peers leads us to revision and transformative discovery as Gerry LaFemina (2006) demonstrates. There is, as yet, no more empirically-tested model of what asynchronous Creative Writing online workshops could look like than the experience-based descriptions of Freiman (2002) or Beck (2004). There are several in Writing (Breuch 2004; Cho \& Schunn 2007) and the outlook is promising.

Synchronous workshops would be logistically challenging and time- and resource-intensive and would involve teleconferencing software like Elluminate or Horizon Wimba, mobile technologies, and/or synchronous audio-videotextual conferencing (AVT) such as that performed by Yergeau, Wozniak and Vandenberg (2008) in their Writing webtext 'Expanding the space of f2f'. It might also involve Virtual Research Environments (VREs), such as those used in blended model doctoral supervision (Mort \& Horsley 2007). VREs can 'allow writers working on opposite sides of the world to simultaneously re-draft - synthesise, even secrete - a document in real time, one of them working at sundown, the other at dawn' (Mort \& Horsley 2007: 39). I can imagine this being effective, focussing on semiotic practices as it does, but can't imagine it being practical. I can, however, begin to rise to the pedagogic challenge of developing writing identities through interaction with class members as resources and mentors. To do so will take us through the constructivist concepts of community of practice and imagined community and segue into poststructural conceptions of identity.

At the 15th Annual Australasian Association of Writing Programs conference, Bell, Cooper and Worthing (2010) asked how effective teaching Creative Writing by distance education is. Their key conclusion - that Creative Writing can indeed be taught effectively by distance education at both the undergraduate and postgraduate levels - supports existing studies within the discipline suggesting the affirmative (Beck 2004; Freiman 2002). Their study, though, points to three needs: the need to provide a sense of belonging to a learning community; the need for prompt and trustworthy feedback, and of course the need to find computer-mediated ways of replicating the benefits of the writing workshop. To some extent, I discuss these throughout this paper, but in the next section will focus mostly on the importance of belonging to a learning community. This takes us to the social constructivists and the assertion that 'people, forming a community, come together because they are able to identify with something - a need, a common shared goal and identity' (Hung \& DerThanq 2001: 3).

\section{Social constructivism and communities of practice}

Discussion of social constructivism invariably begins with the Vygotskian (1978) imperative: higher cognitive processes, acquired initially through social interaction and mediated by language, occur inter-personally, often in the form of discovery, before becoming internalised at an intra-personal level. It is at the intra-personal level that personality becomes an impacting factor, resulting in Csikszentmihalyi's (1996) optimal experience found in individuals with perseverance, flexibility, and curiosity.

In social constructivism, learning is situated, originates in socialisation, then becomes individuated (Hung \& Der-Thanq 2001). Central to this is the pedagogical application of Bruner's (1986) spiral scaffolding to ensure student 
progress is manageable. This is a feature of pedagogical interactions with a high power differential; but opening possibilities for critical friendships supported by tutor-to-student relationships reduces power differentials and helps writers achieve their actual developmental levels. Further, generating texts impacts creative production (Bruner 1986) since it allows writers to develop narrative models stored as autobriographical memory (McAdams 1993). Important, too, is Bruner's (1986) advocacy of Socratic self-interrogation, an ideal strategy for Writing, to create optimum conditions for learning, and applied in ways that are both activity-oriented and culturally responsive.

At the heart of social constructivism is Jean Lave and Etienne Wenger's (1991) notion of 'communities of practice'. These are real or imagined places where potentially expert learning can occur through initially peripheral participation. In their wake, researchers in online pedagogies have devised frameworks for elearning communities:

...In a community, learning occurs as a social process. In an eLearning community, members work together to solve their problems and to improve their communities using knowledge construction media and technology. (Tu \& Corry 2002: 209)

Theoretically, persistent investment in participation can motivate learners to reach their learning goals effectively through the forming of strategic alliances with and within appropriate communities. It has been argued that online postgraduate students need to belong to a learning community in order to achieve optimal learning (LaPointe \& Reisetter 2008: 652). Instructors, therefore, might feel they need to encourage communications between more and less invested individuals. In the Swinburne MA, many students, often experienced and professional writers, are, despite their appetite for selfdiscovery, assets and resources. However, establishing critical friendship with a needy 'mentee' might not bring about the 'reciprocal teaching' Freiman (2002: 4) witnessed (theorised by Cho and Schunn 2007). Critical friendship is partly about learning from quality feedback. When students (strong or weak) feel they are not getting the support and feedback they need, they seek it from other critical friends or the tutor, who is ultimately a member of this community as well as its e-moderator. Failure to realise the tutor is also a community member might result in the dissatisfaction with feedback Bell et al (2010) and Lapointe and Reisetter (2008) report.

In theory participation and sharing leads to willingness for collaboration and mutual critiquing and builds 'sense of community'. This is supported by the words of tutors, reported in Andrew (2009):

Students relax and feel easier, ask more questions, find their own experiences relevant and learn more effectively. Many are amazed at the sense of community that can emerge through the digital environment... For many the sense of community between the students is the most important and valuable aspect of the course.

Tutors can foster sense of community through a range of strategies (Salmon 2003; Palloff \& Platt 2005). 'Sense of community' has best been defined as: 'a feeling that members have of belonging, a feeling that members matter to one another and to the group, and a shared faith that learners' needs will be met through their commitment to be together' (McMillan \& Chavis 1986: 9). They itemised its elements as membership, influence, fulfilment of needs and shared emotional connection (1986: 9). There is evidence of the impact of sharing emotional connection in the voice of a final year student cited in Andrew and Arnold (2011): 'Along the way, I found companions who shared my passion, 
my belief, that this way forward is our particular life journey we must brave. We have supported and held out hands to help one another over those seemingly impossible parts of this journey'. As Rovai wrote: 'learning represents the common purpose of the community as members ... grow to value learning and feel that their educational needs are being satisfied through active participation' (Rovai 2002: 6).

\section{Social constructivism and the 5-stage model}

According to Wenger, learning communities 'make trajectories possible - that is, to the extent they offer a past and a future that can be experienced as a personal trajectory' (Wenger 1998: 215). It is a trajectory of this nature that Gilly Salmon (2000: 29) effectively traces in her 5-stage model of teaching and learning online.

Based on her practice and research in an MBA program at the Open University (UK), Salmon's model is regarded as a one-size-fits-all sequence of pedagogical stages initially for designers and e-moderators. Because of and perhaps in spite of its simplicity, it continues to exert influence. Stage 1, access and motivation, focuses on welcoming student ensuring they are comfortable with the learning interface and its components and unpacking the assessment structure. Stage 2 is labeled online socialisation, although socialisation happens throughout a (Creative) Writing unit or even a program. In Salmon's model, it relates to 'familiarizing and providing bridges between cultural, social and learning environments' (2000: 29) establishing the netiquette and protocols of online learning environment.

It does this by engaging participants, including 'lurkers' and 'outliers', in concise, targeted, non-threatening, disclosure-type, task-based 'e-tivities' created and overseen by e-moderators. Here trust builds, and 'trust cannot be over-emphasised' (2000: 34). Information exchange, where learners appreciate and expand the shared repertoire, is the ideal third stage, though in (Creative) Writing units it never stops and is chronologically and pedagogically inseparable from the fourth, namely knowledge construction. Here participants interact 'in more exposed and participative ways' (2000: 41), collaboration drives the learning forward and tutors motivate, unify, congratulate and challenge. It is at this stage, at approximately week 8, when we present opportunities for critiquing. Stages 3 and 4 map roughly onto Vygotsky's (1978) zone of proximal development, with situated learning combining with Brunerian (1986) scaffolding to create an environment of maximal information flow and learning based upon their (and others') prior knowledge. Development, Stage 5, applies Vygotskian achievement of higher cognitive ground through interaction and ideally creates autonomy. It says, however, little about selfevaluation and reflective practice, grounding it firmly in the present.

As the above paragraph suggests, Salmon's model has a commonsensical, intuitive understanding of online learners' trajectories that makes it feel universal. What it lacks is a sense that 'the work of identity is always going on' (Wenger 1998: 154). Her model, though, lacks space for understanding either the individual and or an individual's desired and imagined communities.

\section{Beyond the constructivist horizon}

In 2004, responding to the canonisation of Salmon's model, Heather Beck wrote that it would be useful to pursue research 'aimed at developing a model 
specifically geared to teaching creative writing online' (36). Such a model would be less monolithic and involve a more complex understanding of writers' identities as unfixed, in flux and open to change. A focus on the personal would coexist with individual learning. Vandermeulen (2011) has produced a timely reminder of the centrality of the personal in Creative Writing via dialogue via the reflection, response, critique and mentorship that characterizes Swinburne's units, To inform such a model as Beck suggests we can turn to Benedict Anderson's (1983) understanding of imagined communities, Markus and Nurius's (1986) notion of future selves and post-structural understandings of identity as complex, unfinished, a site of conflict (Weedon 1997).

According to Anderson (1983), a culture's sense of community is envisaged as an imagined space and individuals idealise community and create a sense of self through these imaginings. We all, and, I think, especially writers, imagine communities where we belong: communities of people who can rightfully be called 'writers' or 'poets', places where we are esteemed and/or prize-winners and/or rich, places of identity. This is supported by the insight of one of the tutors in Andrew (2009): 'Feeling part of the professional writing community can allow students entrée and mentoring in a very competitive and quite nepotistic industry'. There is, Bonny Norton and Yihong Gao (2008) suggest, an immediate connection between learner investment, desires to belong and become, and the construction of identities as learners and members of imagined communities. They maintain 'the people in whom learners have the greatest investment may be the very people who represent or provide access to the imagined community of a given learner' (114). From week 1, imagined communities are already in the 'classroom': As soon as students describe their motivation to study Writing, there are imagined communities: 'I've been an accountant for 20 years, but I'm really a writer' (student in week one). For our students imagined communities might be newsrooms, publishing houses, universities; or they could be rooms of one's own. Understanding our students' imagined communities is crucial to designing and implementing Writing programs, particularly disembodied online ones.

While Writing students envisage might envisage themselves as belonging to imagined communities, they might also possess idealised conceptions of what Markus and Nurius (1986) called 'possible selves'. The notion concerns learners' as yet unrealised potential, drawing not just on their current competencies, but also on their hopes and ambitions. How tutors regard students is important here, as one online tutor (Andrew 2009) says, 'The course encourages them to think of themselves as writers from day 1 - and this is an important step in the development of their practice'. Like imagined communities, possible selves are valuable ways of 'providing bridges between cultural, social and learning environments' (Salmon 2000: 29) and of empowering learners to aspire.

While imaginative capacity is expected in writers, we equally expect their receptive capacities to evolve through feedback, reflection, critique and praise. Resilience and flexibility are as desirable graduate attributes as reflexivity and creativity. The very nature of being and becoming a writer is coterminous with postmodern conceptions of identity as multiple, subject to cultural displacement and shifting axes of power (Reed-Danahay, 1997: 2). Bonny Norton, adapting to a post-structural frame, adds that 'the concept of identity as a site of struggle is a logical extension of the position that identity is multiple and contradictory' (Norton 2000: 127). This is a socio-cultural species of post-structuralism marked by a return to the signifying power of language and its potential to construct our subjectivity (Weedon 1997: 21). 
Colyar (2009: 435), performing a process of 'Becoming writing, becoming writers', remembers Pablo Freire's (1998) envisaging a 'permanent movement of searching' in the acceptance of the unfinished as redolent with possibility. This, she concludes, embodies 'the very possibility of learning' (cited in Colyar 2009: 435), a notion central to Freire's community-based learning pedagogies. Freire (2004), famously, also valorized learning for enabling people to 'make and remake themselves' by 'knowing that they know and knowing that they don't' (15). From post-structuralism and Freire we are reminded of the wisdom of living with non-fixedness in our text and subjectivities and of the need to incorporate this into our pedagogies for online Writing. For Colyar, 'writing is not simply what we 'do,' but also how we become better writers and scholars' (421). For our writers, Wenger's (2008) personal trajectory into imagined communities and possible selves will continue indefinitely and we witness just a fraction of it. As another student writes in her last post: 'There is no full stop to this post, in keeping with a lively future anticipated for the critical friendship network formed by our tutorial group'.

\section{Conclusions}

This study has presented a survey of thinking about how the notions of communities of practice and imagined communities and post-structural insights into flexible writerly identity might impact on the design and delivery on online Writing programs. It has been informed by small-scale research projects contributing to the discussion of how a community-focussed pedagogy can add educational, social and ontological value to students of online Writing, specifically postgraduate Writing (Andrew 2009; Andrew \& Arnold 2010). This narrative suggests online Writing students should be encouraged to become aware of and to voice their investments - their reasons for participating, desires to write, dreams of the identity 'writer'. While online (Creative) Writing students desire a focus on individual voice and identity, the learning community also provides the essential Wengerian elements of support and belonging identified by researchers of online learning communities (Bell et al 2010; LaPointe \& Reisetter 2008; Rovai 2002; Tu \& Corry 2002). Being and becoming self-aware can be empowering, and, for students sharing their imagined communities and future selves can help tutors effectively use a range of targeted pedagogical strategies. Thus, tutors can address learner-writer needs and the element of the 'personal' that Vandermuelen (2011) foregrounds while understanding the multiple identities students hold and desire. (In writing about 'students' I've been conscious of category slippage and aware of the multiple identities they bridge in present and future time: students, learners, online participants, community of practice members, peers, critical friends, people, writers).

In the light of community of practice theory, it is clear that contributing to a community's repertoire can afford learners incidental, invaluable windows into their own creative and supportive potential as well as providing a criticallyfriendly forum for discussion and analysis. The communities created become demand-driven Wengerian places of identity where participants experience learning about their writing voices as a personal trajectory while engaging in situated social acts like peer reviewing, sharing useful hyperlinks and building on others' discussions. Further, the concepts of community of practice and imagined community inform our developing knowledge of the communicative interactions and transactions that characterise virtual learning environments in Writing. 
Collaboration and critique can improve texts. Many studies support this (Breuch 2004; Cho \& Schunn 2007). Yet there remains a need to research more deeply Freiman's (2002) or Beck's (2004) idea that discussion forums can simulate the F2F workshop formats. There is space, particularly, to consider whether a synchronous delivery, with its many logistical issues, offers sufficient pedagogical (and monetary) value compared to asynchronous models that currently resemble peer critiquing with tutor input. I am unconvinced that synchronous deliveries are sustainable, given the current state of Australian universities, driven by workload models and the bastardised buzzwords 'sustainability', 'flexibility' and 'creativity'. In 100\% online programs empirically testing models of online workshopping, which will evolve from the peer critiquing, is a necessity. In blended models, the evidence suggests a strong student orientation towards F2F delivery (Bell et al 2010; Conway-Herron \& Morgan 2008). This points to a need for converged deliveries to strengthen the pedagogical value of online workshopping, destigmatise it and encourage students to invest in their multiple possibilities as Freiman's (2002) students did in intense 3-week blocks creating a different kind of community (7). It could be the unimaginable community we dread but will get.

We - perhaps I - need to think through the non-normative and elastic pedagogies presented in Dianne Donnelly's (2010) study of Creative Writing workshopping and consider whether existing online pedagogy and technology (as outlined by Breuch 2004 and Herrington et al 2009) can support such practices practically and sustainably without the pedagogical sacrifice epitomised by King's assertion about RMIT 'knocking the soul' out of its prestige PWE program. Can online workshops play a beneficial role in interrogating both readerly-writerly texts and any totalizing assumptions they may contain, simultaneously stabilising and destabilising as F2F workshops can? The security of online Writing workshops may lie in AVTs, VLEs and digital technologies still unmastered: imagine the space of Google Documents with voice, multiple dimensions and the possibility to annotate, edit and critique manuscripts in either synchronous or asynchronous time. While we don't want Writing teachers becoming insomniacs and screen slaves, we have a vested interest in preserving and improving our Writing programs for the brave new world of sustainable blended/ flexible and/ or $100 \%$ online deliveries.

Forewarned is forearmed.

\section{Works cited}

Anderson, B 1983 Imagined communities: Reflections on the origin and spread of nationalism, Verso, New York return to text

Andrew, M. 2009 'Postgraduate writing e-communities: De-marginalising remote participants', Margins \& Mainstream. Proceedings AAWP Conference Hamilton 2009: http://aawp.org.au/files/Andrew 0.pdf [accessed 22 March 2012] return to text

Andrew, M 2010 'Strategically maintaining online learning community in a postgraduate writing program', Curriculum, technology \& transformation for an unknown future. Proceedings ascilite 2010 Sydney: 49-59 http://www.ascilite.org.au/conferences/sydney10/procs/Andrew-full.pdf [accessed 21 October 2012] return to text

Andrew, M \& J Arnold 2011 'Collaboration, community, identity: Engaged elearning and e-teaching in an online writing course', Changing Demands, Changing Directions. Proceedings ascilite 2011 Hobart: 106-117 
http://www.ascilite.org.au/conferences/hobart11/downloads/papers/Andrewfull.pdf [accessed 21 October 2012] return to text

Beck, H 2004 'Teaching creative writing online', New Writing: The International Journal for the Practice and Theory of Creative Writing 1, 1: 2336 return to text

Bell, C, J Cooper \& M Worthing 2010 'Teaching creative writing by distance education: how effective is it?', in Strange bedfellows: Refereed Conference Papers of the 15th Annual AAWP Conference Melbourne 2010 http://aawp.org.au/publications-aawp [accessed 22 March 2012] return to text

Bizzaro, P 2010 'Workshop: an ontological study', in D Donnelly (ed) Does the writing workshop still work? Multilingual Matters, Clevedon: 36-51 return to $\underline{\text { text }}$

Breuch, LA 2004 Virtual peer review: Teaching and learning about writing in online environments, State University of New York Press, Albany return to text

Bruner, J 1986 Actual minds, possible worlds, Harvard University Press, Cambridge, MA return to text

Chang, H 2008 Autoethnography as method, Left Coast, Walnut Creek, CA return to text

Cho, K, \& CD Schunn 2007 'Scaffolded writing and rewriting in the discipline: A web-based reciprocal peer review system', Computers \& Education 48, 3: 409-426 return to text

Conway-Herron, J \& C Morgan 2008 'Flexible delivery: Creative environments', Creativity and Uncertainty. Proceedings AAWP Conference Sydney 2008: http://aawp.org.au/files/Conway-Morgan.pdf [accessed 22 March 2012] return to text

Csikszentmihalyi, M 1988 'Society, culture, person: A systems view of creativity', in RJ Sternberg (ed) The nature of creativity, Cambridge University Press, New York: 325-329 return to text

Day, C, A Leahy \& S Vanderslice 2011 'Where Are We Going Next? A Conversation about Creative Writing Pedagogy', Fiction Writers' Review: http://fictionwritersreview.com/essays/where-are-we-going-next-aconversation-about-creative-writing-pedagogy-pt-1 and http://fictionwritersreview.com/essays/where-are-we-going-next-aconversation-about-creative-writing-pedagogy=pt-2 [accessed 22 March 2012] $\underline{\text { return to text }}$

Donnelly, D (ed) 2010 Does the writing workshop still work? Multilingual Matters, Clevedon return to text

Freiman, M 2002 'Learning through Dialogue: Teaching and assessing creative writing' TEXT 6, 2 (October): http://www.textjournal.com.au/oct02/freiman.htm [accessed 22 March 2012] return to text

Freire, P 2004 Pedagogy of indignation, Paradigm, Boulder, CO return to text

Hatton, N \& D Smith 2005 'Reflection in teacher education: Toward definition and implementation', Teaching and Teacher Education II: 33-49 return to text 
Healey, S 'The Rise of Creative Writing \& the New Value of Creativity', The Writer's Chronicle 41 (February): 4 return to text

Herrington, A, K Hodgson \& C Moran 2009 Teaching the New Writing:

Technology, Change, and Assessment in the 21st Century Classroom, Teacher's College Press, New York return to text

Hung, D \& C Der-Thanq 2001 'Situated cognition, Vygotskian thought and learning from the communities of practice perspective: Implications for design of web-based e-learning', Educational Media International 38, 1: 3-12 return to $\underline{\text { text }}$

Ivanic, R 1998 Writing and identity, John Benjamins, Amsterdam return to text

King, M 2012 'Renowned RMIT TAFE writing program dead', ON LINE Opinion Australia's e-journal of social and political debate: http://www.onlineopinion.com.au/view.asp?article=13235 [accessed $22 \mathrm{March}$ 2012] return to text

LaFemina, G 2006 'Fields of inquiry: Poetic composition, revision, and transcendence', TEXT 10, 2 (April):

http://www.textjournal.com.au/oct06/lafemina.htm [accessed 22 March 2012] return to text

Lapointe, L \& M Reisetter 2008 'Belonging Online: Students' perceptions of the value and efficacy of an online learning community', International Journal on E-Learning 7, 4: 641-55 return to text

Lave, J \& E Wenger 1991 Situated learning: Legitimate peripheral participation, Cambridge University Press, Cambridge return to text

Markus, H \& P Nurius 1986 'Possible selves', American Psychologist 41: 954969 return to text

McAdams, DP 1993 The stories we live by: Personal myths and the making of the self, Morrow, New York return to text

McMillan, DW \& DM Chavis 1986 'Sense of community: A definition and theory', Journal of Community Psychology 14, 1: 6-23 return to text

Mort, G \& L Horsely 2007 'The implied supervisor', The International Journal of Learning 14, 4: 37-44 return to text

Norton, B 2000 Identity and language learning: Gender, ethnicity, and educational change, Longman, London return to text

Norton, B \& Y Gao 2008 'Identity, investment and Chinese learners of English', Journal of Asian Pacific Communication 18, 1: 109-120 return to text

Palloff, R \& K Platt 2005 Collaborating online: learning together in community, John Wiley, London return to text

Polkinghorne, DE 1998 Narrative Knowing and the Human Sciences, State University of New York Press, New York return to text

Reed-Danahay, D (ed) 1997 Auto-Ethnography: Rewriting the self and the social, Berg, Oxford return to text

Renner, C 2008 'Celebrating 20 years: RMIT's professional writing and editing program,' Edjournal 3, 2: http://emedia.rmit.edu.au/edjournal/node/366 
[accessed 22 March 2012] return to text

Rovai, AP 2002 'Building sense of community at a distance', International Review of Research in Open and Distance Learning 3, 1: 1-16 return to text

Salmon, G 2003 E-tivities, Kogan Page, London return to text

Salmon, G 2000 E-moderating, Routledge Falmer, London return to text

Tu, C-H \& M Corry 2002 'E-Learning communities', Quarterly Review of Distance Education, 3, 2: 207-218 return to text

Vandermuelen, C 2011 Negotiating the personal in creative writing, Multilingual Matters, Clevedon return to text

Vanderslice, S 2006 'Workshopping', in G Harper (ed) Teaching creative writing, Continuum, London: 147-157 return to text

Vygotsky, LS 1978 Mind in society: The development of higher psychological processes, Harvard University Press, Cambridge, MA return to text

Weedon, C 1997 Feminist practice and poststructuralist theory, Blackwell, Oxford return to text

Wenger, E 1998 Communities of practice, Cambridge University Press, Cambridge return to text

Yergeau, M, K Wozniak \& P Vandenberg 2008 'Expanding the space of f2f: Writing centers and audio-visual-textual conferencing', Kairos 13, 1: http://kairos.technorhetoric.net/13.1/topoi/yergeau-et-al/index.html [accessed 22 March 2012] return to text

Martin Andrew currently lectures in Education at Victoria University in Melbourne in a post that includes language learning and creative methodologies. For four years he taught and researched (Creative) Writing at Swinburne University of Technology, undertaking a study of the application of community-focussed theories to online writing practices. Initially a scholar of Renaissance drama and historical linguistics, he writes in a variety of media and researches identity in writing, community engagement and cultural learning, researching his own practice whever possible.

\section{TEXT}

Vol 16 No 2 October 2012

http://www.textjournal.com.au

Editors: Nigel Krauth, Kevin Brophy \& Enza Gandolfo text@textjournal.com.au 